\title{
RANCANG BANGUN APLIKASI PERPUSTAKAAN PADA SMP NEGERI 1 CIASEM SUBANG
}

\author{
${ }^{1}$ Gita Rahmayanti, ${ }^{2}$ Robi Sopandi, ${ }^{3}$ Mohammad Syamsul Aziz, ${ }^{4}$ M. Qomaruddin \\ E-mail : ${ }^{1}$ grahmayanti@gmail.com ${ }^{2}$ robi.rbs@ nusamandiri.ac.id \\ ${ }^{3}$ mohammad.myz@nusamandiri.ac.id, ${ }^{4}$ qomaruddin.mqn@ nusamandiri.ac.id
}

\begin{abstract}
Abstrak
Perpustakaan sekolah adalah suatu tempat dimana para siswa memperoleh akses terhadap informasi dan pengetahuan. Perpustakaan merupakan salah satu sarana pendukung untuk melakukan pembelajaran melalui bahan pustaka yang sesuai dengan kurikulum sekolah. Perpustakaan di SMP Negeri 1 Ciasem sangat membutuhkan adanya suatu program yang dapat menunjang pengelolaan di perpustakaan tersebut agar lebih maksimal. Untuk itulah peneliti mencoba mambuat Penelitian mengenai program perpustakaan di SMP Negeri 1 Ciasem yang sampai saat ini belum terkomputerisasi. SMP Negeri 1 Ciasem merupakan salah satu Sekolah Menegah Pertama Negeri yang ada di Kabupaten Subang. Sistem pengelolaan perpustakaan yang ada di SMP Negeri 1 Ciasem ini masih dilakukan secara manual, mulai dari pencatatan buku masuk, pencatatan transaksi peminjaman dan pengembalian, penyimpanan data-data, hingga pembuatan laporan, sehingga terdapat kemungkinan terjadi kesalahan ketika pencatatan data, kurang akuratnya laporan yang dibuat dan kesulitan dalam pencarian data-data yang diperlukan. Rancang Bangun Aplikasi ini merupakan solusi yang terbaik untuk memecahkan permasalahan yang ada pada instansi ini, serta dengan sistem yang terkomputerisasi dapat memaksimalkan pengelolaan di perpustakaan tersebut. Sistem yang terkomputerisasi lebih baik daripada sistem yang manual agar berjalan lebih efektif dan efisien serta sistem pengelolaan perpustakaan yang sekarang lebih kondusif dibandingkan dengan sistem yang terdahulu.
\end{abstract}

Kata Kunci: Rancang Bangun Aplikasi, Program Perpustakaan

\begin{abstract}
The school library is a place where students gain access to information and knowledge. Library is one of the supporting facilities for learning through library materials in accordance with the school curriculum. The library in SMP Negeri 1 Ciasem is in need of a program that can support the management in the library to be more leverage. That is why the writer tries to make her Final Assignment about the library program in SMP Negeri 1 Ciasem which until now has not been computerized. SMP Negeri 1 Ciasem is one of the First State Secondary Schools in Subang Regency. The library management system in SMP Negeri 1 Ciasem is still done manually, starting from recording of incoming book, recording of borrowing and repayment transaction, data storage, to report making, so that there may be mistake when recording data, less accurate report made and difficulty in searching the necessary data. The design of this program is the best solution to solve the problems that exist in this agency, and with a computerized system can maximize the management in the library. The computerized system is better than the manual system to run more effectively and efficiently and the library management system is now more conducive than the previous system.
\end{abstract}

Keywords: Application Design, Library Program 


\section{Pendahuluan}

Perpustakaan adalah tempat untuk mengumpulkan, menyimpan, serta mengelola sumber infomasi berupa buku-buku, majalah, artikel dan lain-lain untuk digunakan oleh pembaca sebagai penambah wawasan. Perpustakaan sebagai salah satu sumber informasi memiliki peranan penting dalam hal mencerdaskan kehidupan bangsa ini, khususnya para pelajar. Oleh karena itu, perpustakaan sekolah merupakan hal yang wajib ada disetiap instansi pendidikan, karena perpustakaan merupakan penunjang proses kegiatan belajar mengajar bagi para siswa. Dengan meningkatkan peran perpustakaan diharapkan dapat memaksimalkan pendidikan bagi para siswa.

Perpustakaan di SMP Negeri 1 Ciasem berdiri sejak tahun 2002. Perpustakaan ini memiliki koleksi yang cukup lengkap, namun dalam hal pengelolaannya masih menggunakan sistem konvensional dengan mencatatnya secara terpisah-pisah. Hal tersebut mengakibatkan pengelola kesulitan dalam hal pencatatan setiap detail datanya. Dalam hal transaksi peminjaman dan pengembalian pun pengelola perpustakaan hanya mencatat dalam sebuah buku, sehingga sering terjadi kehilangan buku dikarenakan sistem pengelolaan yang kurang baik. Dengan adanya pencatatan secara konvensional tersebut, butuh waktu yang cukup lama untuk mencari data-data ataupun buku-buku yang akan dipinjam oleh siswa. Dari uraian di atas, dapat dianalisa bahwa pelayanan di perpustakaan SMP Negeri 1 Ciasem ini kurang efektif dan efisien. Oleh karena itu, diperlukan suatu rancang bangun aplikasi yang lebih baik guna meningkatkan keefektifan sistem perpustakaan ini.

Seiring dengan berkembangnya teknologi dan informasi saat ini, maka hal ini dapat dimanfaatkan untuk merancang dan membangun program perpustakan berbasis desktop. Diharapkan setelah adanya peningkatan sistem yang telah terkomputerisasi ini pengelolaan perpustakaan di SMP Negeri 1 Ciasem dapat meningkatkan pelayanan agar leboh efektif dan efisien. Atas dasar identifikasi masalah yang telah dipaparkan diatas, maka rumusan masalah pada penelitian ini adalah bagaimana membuat program perpustakaan pada sekolah dapat meningkatkan keefektifannya.

\section{Tinjauan Pustaka}

\section{Perpustakaan}

Menurut Sutarno dalam Diah (2016:229), "perpustakaan adalah sarana lembaga pendidikan yang sangat demokratis karena menyediakan sumber belajar sesuai dengan kebutuhan masyarakat, dan melayaninya tanpa membedakan suku babngsa, agama yang dianut, jenis kelamin, latar belakang dan tingkat sosial, umur dan pendidikan serta perbedaan lainnya".

2. ERD

Menurut Sukamto dan M. Shalahuddin (2018:53), "ERD adalah bentuk paling awal dalam melakukan perancangan basis data relasional".

\section{Basis Data}

Menurut Yanto (2016:11), basis data merupakan "kumpulan data yang saling berhubungan yang disimpan secara bersama sedemikian rupa dan tanpa pengulangan (redudansi), untuk memenuhi berbagai kebutuhan".

\section{FlowChart}

Menurut Ardhana dalam Mirawati dan Purnia (2015:387), mengemukakan bahwa "Flowchart adalah bagan-bagan yang mempunyai arus atau alur secara terurut yang menggambarkan langkah-langkah penyelesaian suatu masalah".

Menurut Sitorus (2015:14), "Flowchart menggambarkan urutan logika dari suatu prosedur pemecahan masalah, sehingga Flowchart merupakan langkah-langkah penyelesaian masalah yang dituliskan dalam simbol-simbol tertentu".

\section{Pengkodean}

Menurut Ariansa (2015), "Pengkodean (Encoding) adalah proses perubahan karakter data yang akan dikirim dari suatu titik ke titik lain dengan kode yang dikenal oleh setiap terminal yang ada, dan menjadikan setiap karakter data dalam sebuah informasi digital ke dalam bentuk biner agar dapat ditransmisikan. Suatu terminal yang berbeda menggunakan kode biner yang berbeda untuk mewakili setiap 
karakter". Kode dapat dibuat dalam berbagai struktur kode yang berbeda. Setiap struktur mempunyai kelebihan dan kelemahan (Shatu, 2016:108).

\section{Metode Penelitian}

Metode penelitian yang digunakan oleh peneliti dalam melakukan penelitian, yaitu;

\section{Teknik Pengumpulan Data}

Teknik pengumpulan data yang digunakan oleh peneliti dalam melakukan pengumpulan data untuk pembuatan penelitian adalah:

1. Observasi

Peneliti melakukan observasi secara langsung ke SMP Negeri 1 Ciasem untuk mengamati proses pembuatan kartu anggota, proses penelitian buku masuk, proses peminjaman buku, proses pengembalian buku, serta pembuatan laporan di perpustakaan SMP Negeri 1 Ciasem.

2. Wawancara

Peneliti melakukan wawancara dengan Ibu Neneng Rohatin selaku kepala perpustakaan mengenai sejarah SMP Negeri 1 Ciasem dan perpustakaannya, struktur organisasi dan fungsinya, dan tentang sistem pengelolaan yang saat ini dilakukan di perpustakaan SMP Negeri 1 Ciasem.

3. Studi Pustaka

Dengan terbatasnya ilmu yang peneliti miliki, maka dalam penelitian penelitian ini peneliti ditunjang dengan berbagai literatur seperti buku-buku tentang basis data, pemrograman microsoft visual studio 2010, rekayasa perangkat lunak, bahasa pemrograman, jurnal tentang program, bahasa pemrograman.

\section{Metode Pengembangan Perangkat Lunak}

Metode yang digunakan pada pengembangan perangkat lunak ini menggunakan model waterfall Sukamto dan M. Shalahuddin (2018:28) yang terbagi menjadi lima tahapan, yaitu:

a) Analisis Kebutuhan

Dalam penelitian ini peneliti menganalisa kebutuhan yang diperlukan guna merancang sebuah program perpustakaan. Kebutuhan tersebut berupa data anggota, data buku, data transaksi peminjaman dan pengembalian, serta laporan dari transaksi peminjaman dan pengembalian.

b) Desain

Dalam penelitian penelitian ini peneliti menggunakan ERD (Entity Relationship Diagram) dan LRS (Logical Record Structured) untuk perancangan database. Serta, Flowchart untuk Rancang Bangun Aplikasi.

c) Pembuatan Kode Program

Desain harus ditranslasikan ke dalam program perangkat lunak. Dalam hal ini peneliti menggunakan bahasa pemrograman microsoft visual studio 2010 dan mysql sebagai software database.

d) Pengujian

Dalam penelitian penelitian ini peneliti menggunakan black box testing pada Form login, Form user, Form anggota, Form buku, Form peminjaman, Form pengembalian.

e) Pendukung (Support) atau Pemeliharaan (Maintenance)

Dalam program perpustakaan yang peneliti buat dibutuhkan pemeliharaan seperti backup data secara berkala, menata ulang harddisk dengan scan disk dan defrag secara berkala agar program dapat berjalan dengan baik.

\section{Hasil Penelitian dan Pembahasan}

\section{Analisa Kebutuhan}

SMP Negeri 1 Ciasem yang berlokasi di Jalan Jendral Ahmad Yani No 14 Sukamandi Kecamatan Ciasem Kabupaten Subang, dari hasil observasi pada SMP Negeri 1 Ciasem tersebut bahwa pengolahan data pada bagian perpustakaan nya masih dilakukan secara manual. Pencatatan data seperti data anggota, data buku, data transaksi peminjaman, data transaksi pengembalian dan pembuatan laporan dilakukan secara konvensional atau secara manual. Dengan kondisi tersebut ditemukan beberapa kekurangan diantaranya sering terjadi kesalahan dalam menginput data serta proses pencatatan transaksi masih secara konvensional dengan menggunakan catatan buku yang suatu saat bisa terjadi penduplikasian data. 
Menyadari kekurangan tersebut maka diperlukan sebuah program aplikasi yang dapat digunakan untuk mencatat semua data yang paling utama pada transaksi peminjaman dan pengembalian. Oleh karena itu peneliti membuat sebuah Aplikasi Perpustakaan pada SMP Negeri 1 Ciasem untuk memudahkan kepada pengguna.

Aplikasi Perpustakaan adalah salah satu solusi keterbatasan ini. Adapun kebutuhan dalam aplikasi ini yaitu Admin. Admin sebagai super user atau pengguna yang dapat mengelola semua data dalam aplikasi perpustakaan ini, mencakup menambah, mencari, mengubah, dan menghapus pada menu data anggota, data buku dan data akses pengguna sedangkan untuk mengelola menu transaksi peminjaman dan transaksi pengembalian, user dapat menambah, dan mencetak, sedangkan pada menu laporan user dapat melihat dan mencetak pada menu laporan data buku, laporan transaksi peminjaman serta laporan transaksi pengembalian.

\section{Entity Relationship Diagram}

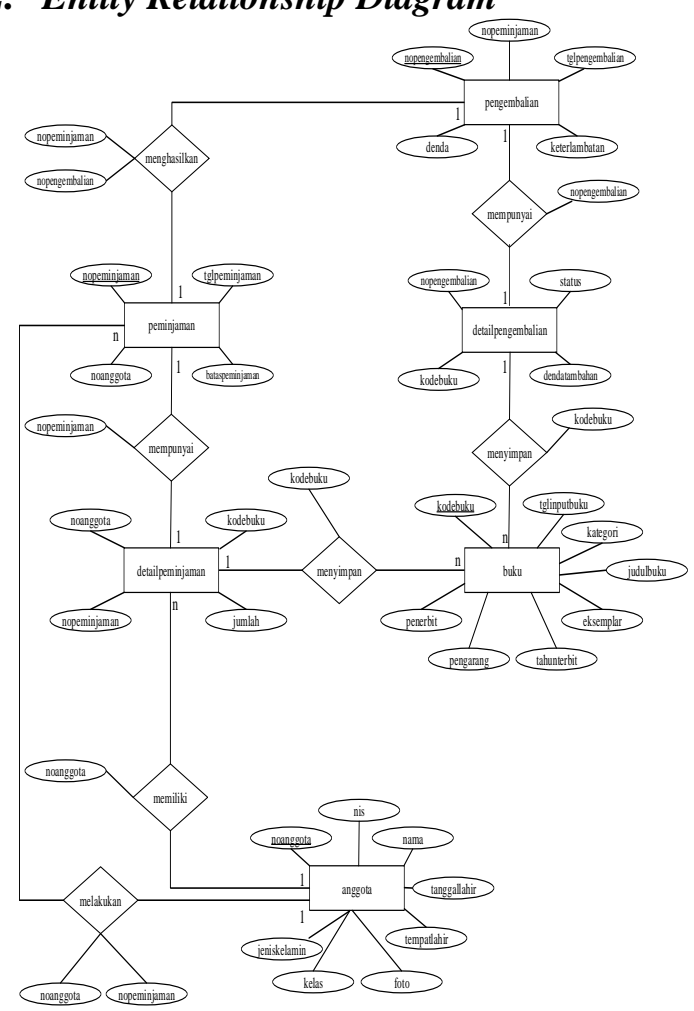

Gambar 1. Entity Relationship Diagram

\section{Logical Record Structure}

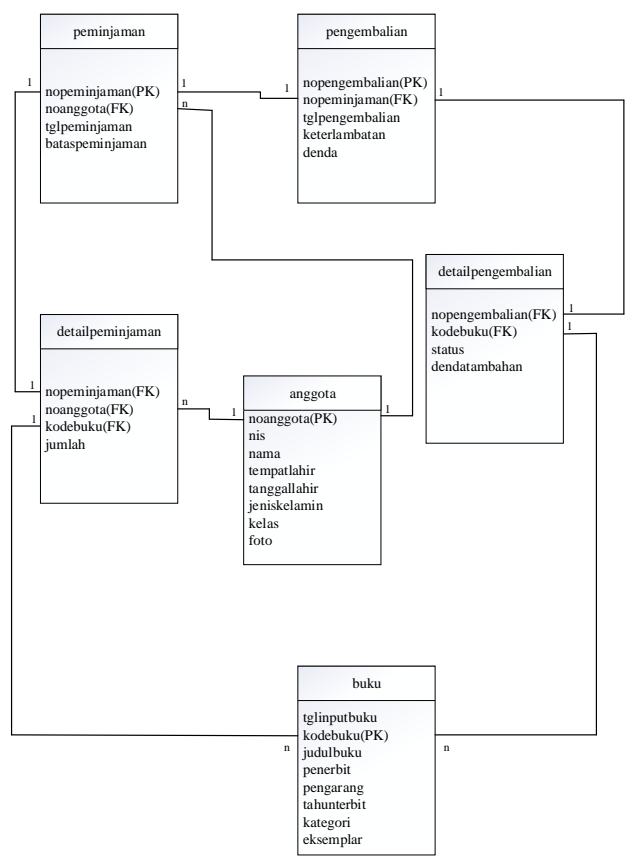

Gambar 2. Logical Record Structure

4. Spesifikasi File

a) Spesifikasi File User

Tabel 1. Spesifikasi File User

\begin{tabular}{|l|l|l|l|l|l|}
\hline No & Elemen Data & Akronim & Tipe & Panjang & Keterangan \\
\hline 1. & Kode User & kodeuser & Char & 10 & Primary Key \\
\hline 2. & Nama User & namauser & Varchar & 20 & \\
\hline 3. & Password & password & Varchar & 35 & \\
\hline 4. & Hakaksses & hakakses & Varchar & 5 & \\
\hline
\end{tabular}

b) Spesifikasi File Anggota

Tabel 2. Spesifikasi File Anggota

\begin{tabular}{|l|l|l|l|l|l|}
\hline$N_{0}$ & Elemen Data & Akronim & Tipe & Panjang & Keterangan \\
\hline 1. & No Anggota & noanggota & Char & 10 & Primary Key \\
\hline 2. & NIS & nis & Char & 10 & \\
\hline 3. & Nama Siswa & nama & Varchar & 25 & \\
\hline 4. & Tempat Lahir & tempatlahir & Varchar & 15 & \\
\hline 5. & Tanggal Lahir & tanggallahir & Date & & \\
\hline 6. & Jenis Kelamin & jeniskelamin & Char & 1 & \\
\hline 7. & kelas & kelas & Varchar & 4 & \\
\hline 8. & foto & foto & Blob & & \\
\hline
\end{tabular}


c) Spesifikasi File Buku

Tabel 3. Spesifikasi File Buku

\begin{tabular}{|l|l|l|l|l|l|}
\hline$N_{0}$ & Elemen Data & Akronim & Tipe & Panjang & Keterangan \\
\hline 1. & $\begin{array}{l}\text { Tanggal Input } \\
\text { Buku }\end{array}$ & tglinputbuku & Date & & \\
\hline 2. & Kode Buku & kodebuku & Char & 7 & Primary Key \\
\hline 3. & Judul Buku & judulbuku & Varchar & 25 & \\
\hline 4. & Penerbit & penerbit & Varchar & 20 & \\
\hline 5. & Pengarang & pengarang & Varchar & 20 & \\
\hline 6. & Tahun Terbit & tahunterbit & Char & 4 & \\
\hline 7. & Kategori & kategori & Varchar & 20 & \\
\hline 8. & Eksemplar & eksemplar & Int & & \\
\hline
\end{tabular}

d) Spesifikasi File Peminjaman

Tabel 4. Spesifikasi File Peminjaman

\begin{tabular}{|l|l|l|l|c|l}
\hline No & Elemen Data & Akronim & Tipe & Panjang & Keterangan \\
\hline 1. & No Peminjaman & nopeminijaman & Char & 10 & Primary Key \\
\hline 2. & No Anggota & noanggota & Char & 10 & Foreign Key \\
\hline 3. & Tanggal Peminiaman & tglpeminjaman & Date & & \\
\hline 4. & Batas Peminijaman & batasseminiaman & Date & & \\
\hline
\end{tabular}

e) Spesifikasi File Detail Peminjaman

Tabel 5. Spesifikasi File Detail

Peminjaman

\begin{tabular}{|l|l|l|l|c|l|}
\hline No & Elemen Data & Akrouim & Tipe & Panjang & Keterangan \\
\hline 1. & No Peminjaman & nopeminjaman & Char & 10 & Foreign Key \\
\hline 2. & No Anggota & noanggota & Char & 10 & Foreign Key \\
\hline 3. & Kode Buku & kodebuku & Char & 7 & Foreign Key \\
\hline 4. & Jumlah & jumlah & Int & & \\
\hline
\end{tabular}

f) Spesifikasi File Pengembalian

Tabel 6. Spesifikasi File Pengembalian

\begin{tabular}{|l|l|l|l|c|l|}
\hline$N_{0}$ & Elemen Data & Akronim & Tipe & Panjang & Keterangan \\
\hline 1. & No Pengembalian & nopengembalian & Char & 10 & Primary Key \\
\hline 2. & No Peminjaman & nopeminjaman & Char & 10 & Foreign Key \\
\hline 3. & Tanggal Pengembalian & tglpengembalian & Date & & \\
\hline 4. & Keterlambatan & keterlambatan & Int & & \\
\hline 5. & Denda & denda & Double & & \\
\hline
\end{tabular}

g) Spesifikasi File Detail Pengembalian

Tabel 7. Spesifikasi File Detail

Pengembalian

\begin{tabular}{|l|l|l|l|c|l|}
\hline No & Elemen Data & Akronim & Tipe & Panjang & Keterangan \\
\hline 1. & No Pengembalian & nopengembalian & Char & 10 & Foreign Key \\
\hline 2. & Kode Buku & kodebuku & Char & 7 & Foreign Key \\
\hline 3. & Status & status & Varchar & 10 & \\
\hline 4. & Denda Tambahan & dendatambahan & Double & & \\
\hline
\end{tabular}

\section{HIPO}

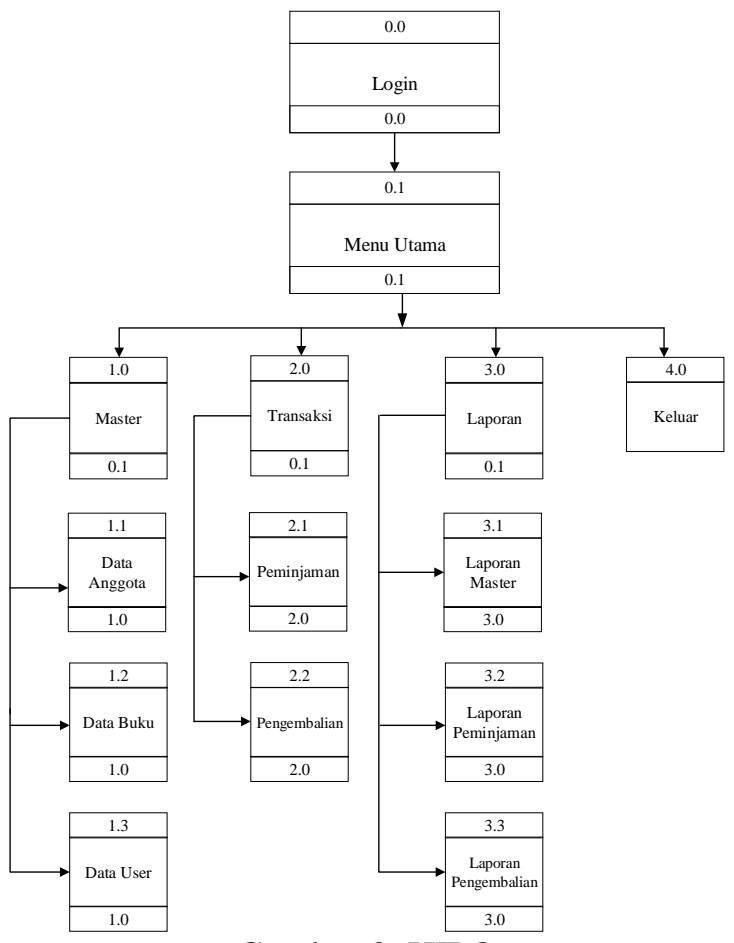

Gambar 3. HIPO

\section{Flowchart}

a) Form Login

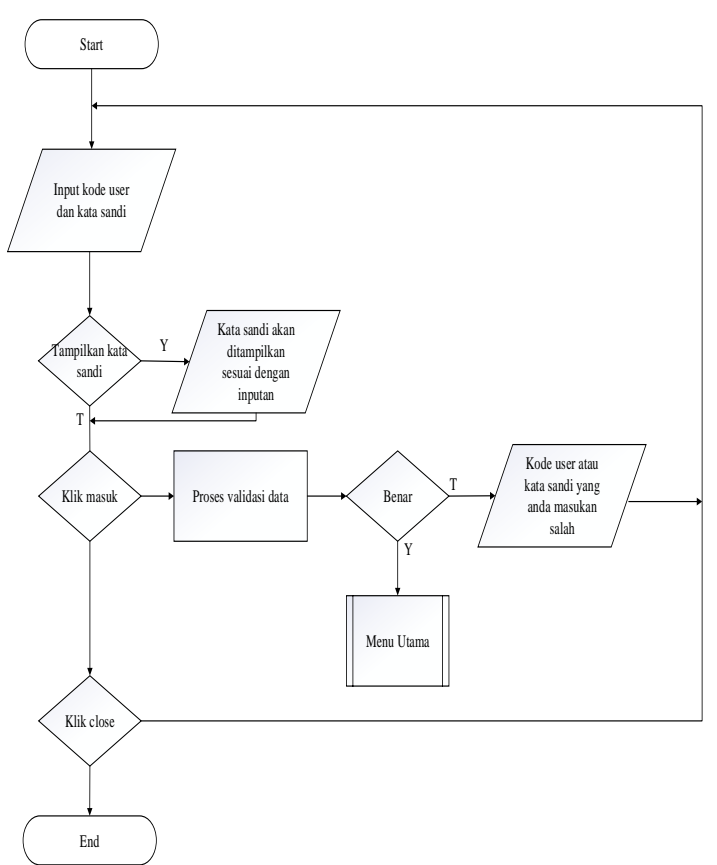

Gambar 4. Flowchart Form Login 
b) Form Menu Utama

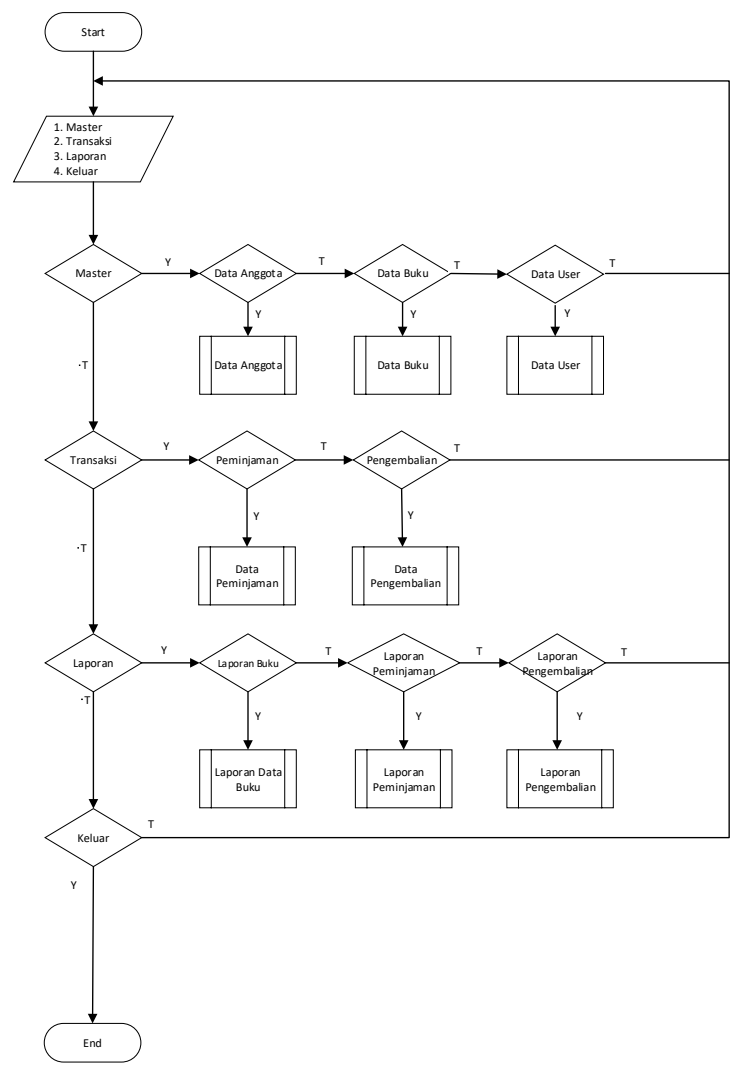

Gambar 5. Flowchart Form Menu Utama

c) Form Data Anggota

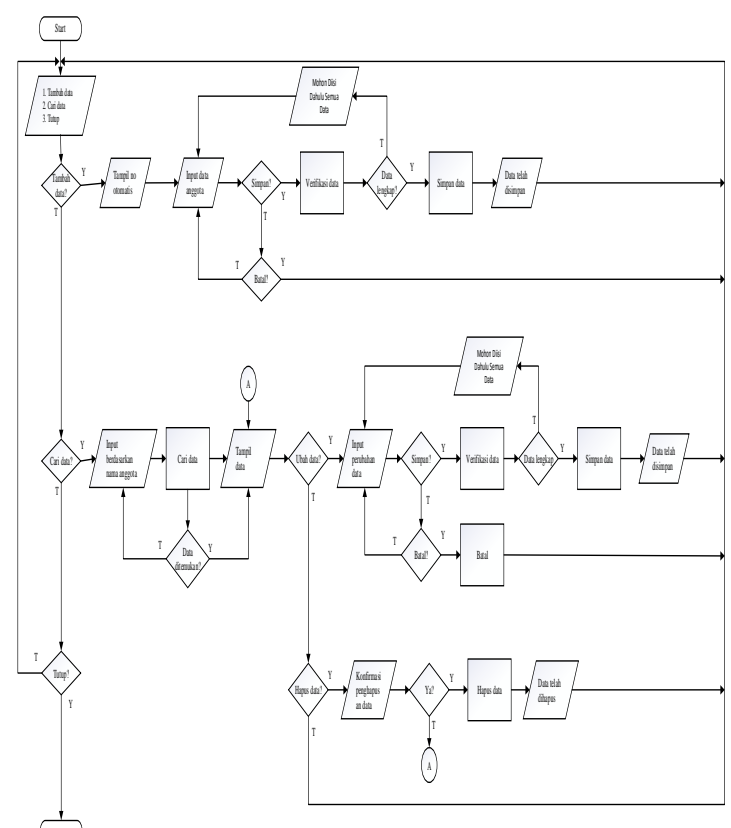

Gambar 6. Flowchart Form Data Anggota d) Form Peminjaman

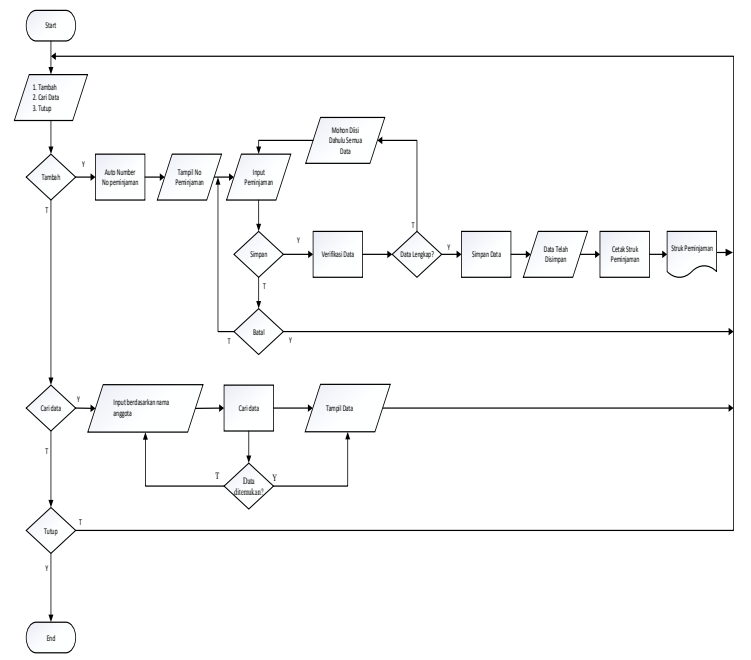

Gambar 7. Flowchart Form Peminjaman

\section{Pengkodean}

Di dalam penelitian penelitian ini, peneliti menggunakan macam-macam kode sebagai berikut:

a) Nama Kode : Kode User

Fungsi : Untuk mengetahui kode user

Panjang : 5 Digit

Tipe : Karakter

Format :

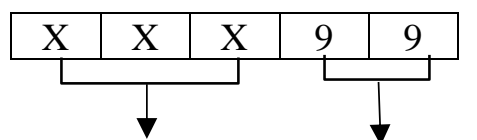

Inisial Kode User Nomor Urut

Contoh:

\begin{tabular}{|l|l|l|l|l|}
\hline $\mathrm{U}$ & $\mathrm{S}$ & $\mathrm{R}$ & 0 & 1 \\
\hline
\end{tabular}

Keterangan:

USR : User

$01 \quad$ : Urutan user ke satu

b) Nama Kode : Kode Buku

Fungsi : Untuk mengetahui kode buku Panjang : 7 Digit

Tipe : Karakter

Format : 


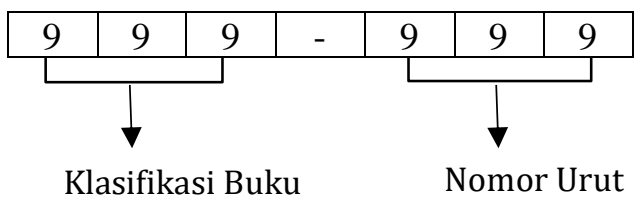

Contoh:

Keterangan:

410

: Klasifikasi buku linguistik/bahasa

003 : Urutan buku ke tiga

c) Nama Kode : Nomor Anggota Fungsi : Untuk mengetahui nomor anggota

Panjang : 5 Digit

Tipe : Karakter

Format :

\begin{tabular}{|c|c|c|c|c|}
\hline 9 & 9 & 9 & 9 & 9 \\
\hline \\
$\substack{\text { Tahun Daftar } \\
\text { Anggota }}$ & \multicolumn{3}{|c|}{ Nomor Urut } \\
\hline
\end{tabular}

Contoh:

Keterangan:

18 : Tahun daftar anggota

001 : Urutan anggota ke satu

d) Nama Kode : Nomor Peminjaman

Fungsi : Untuk mengetahui nomor peminjaman

Panjang : 8 Digit

Tipe : Karakter

Format :

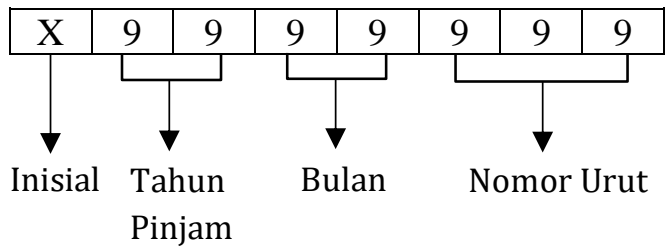

Contoh:

\begin{tabular}{|l|l|l|l|l|l|l|l|}
\hline $\mathrm{P}$ & 1 & 8 & 0 & 5 & 0 & 0 & 1 \\
\hline
\end{tabular}

Keterangan:

$\begin{array}{ll}\mathrm{P} & \text { : Pinjam } \\ 18 & \text { : Tahun Pinjam } \\ 05 & \text { : Bulan Pinjam } \\ 001 & \text { : Urutan peminjaman ke satu }\end{array}$

\section{Spesifikasi Sistem Komputer}

Untuk memperoleh kemampuan yang optimal dalam pengolahan data diperlukan aspek dasar yaitu perangkat keras dan perangkat lunak yang saling berkaitan satu dengan yang lainnya sehingga tidak dapat dipisahkan, karena suatu sistem komputerisasi tidak akan berjalan tanpa salah satu aspek tersebut. Perangkat lunak dan perangkat keras harus dapat menunjukan kerja yang baik dan sesuai dengan yang diharapkan.

a) Perangkat Keras (Hardware)

Perangkat keras atau hardware adalah serangkaian unsur-unsur yang terdiri dari beberapa perangkat keras yang membentuk suatu sistem komputer yang digunakan untuk mengoperasikan proses kerja pemakai.

Peneliti mengusulkan untuk menggunakan perangkat keras atau hardware sesuai dengan kemampuan tanpa harus menggunakan tipe tertentu dengan harga yang lebih mahal. Namun disarankan menggunakan perangkat keras dengan kemampuan yang tepat guna. Spesifikasi sarana pendukung perangkat keras adalah sebagai berikut:

$\begin{array}{lll}\text { a. Processor } & \text { : Pentium IV } \\ \text { b. Memory Size } & \text { : } 2.00 \text { GB (RAM) } \\ \text { c. Hard Disk } & \text { : } 80 \text { GB } \\ \text { d. Mouse } & \text { : Standart Mouse } \\ \text { e. Keyboard } & \text { : 102 Keys } \\ \text { f. Monitor } & \text { : SVGA 16" } \\ \text { g. Printer } & \text { : Inkjet }\end{array}$

b) Perangkat Lunak (Software)

Perangkat lunak atau software serangakaian unsur-unsur yang terdiri dari beberapa perngakat lunak yang membentuk suatu sistem komputer yang digunakan untuk mengoperasikan proses kerja pemakai. Fungsi perangkat lunak ini adalah untuk mengidentifikasi dan menyiapkan aplikasi program sehingga tata kerja seluruh peralatan komputer dapat terkontrol, serta membuat pekerjaan lebih efisien. Jadi pemakaian komputer tidak lepas dari perangkat-perangkat tersebut yang saling berhubungan dan terkait. Adapun perangkat lunak yang digunakan adalah sebagai berikut:
a. Sistem Operasi Windows Seven 7
b. Program Aplikasi Microsoft Visual Studio 2010
c. Program Aplikasi XAMPP 
d. Program Aplikasi Crystal Report

\section{Impelementasi}

a) Form Login

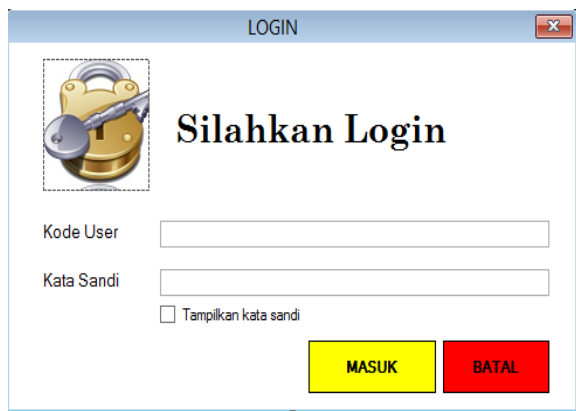

Gambar 8. Form Login

b) Form Menu Utama

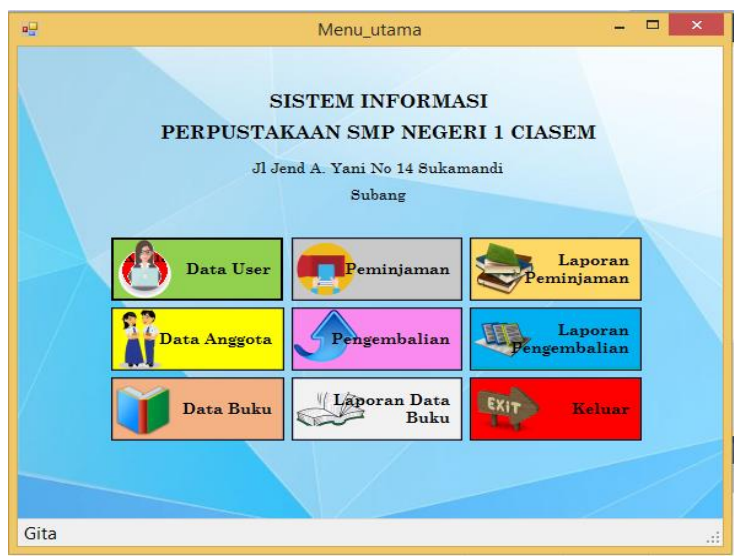

Gambar 9. Form Menu Utama

c) Form Data Anggota

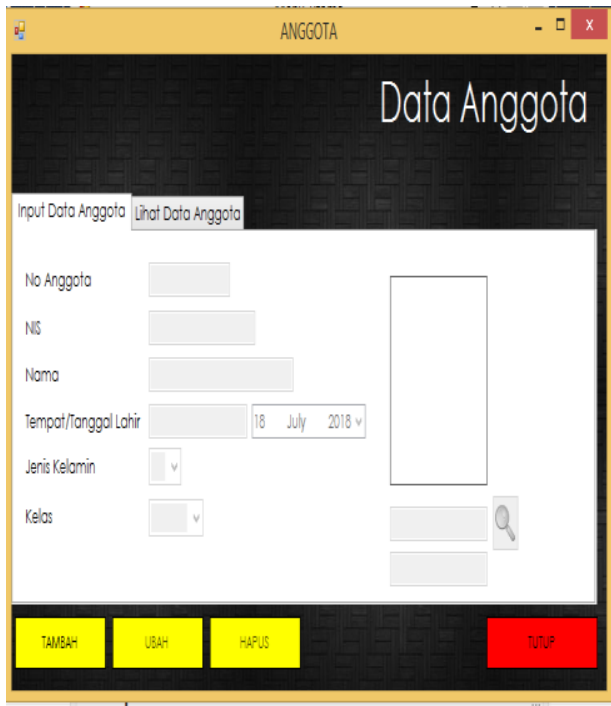

Gambar 10. Form Data Anggota d) Form Data Buku

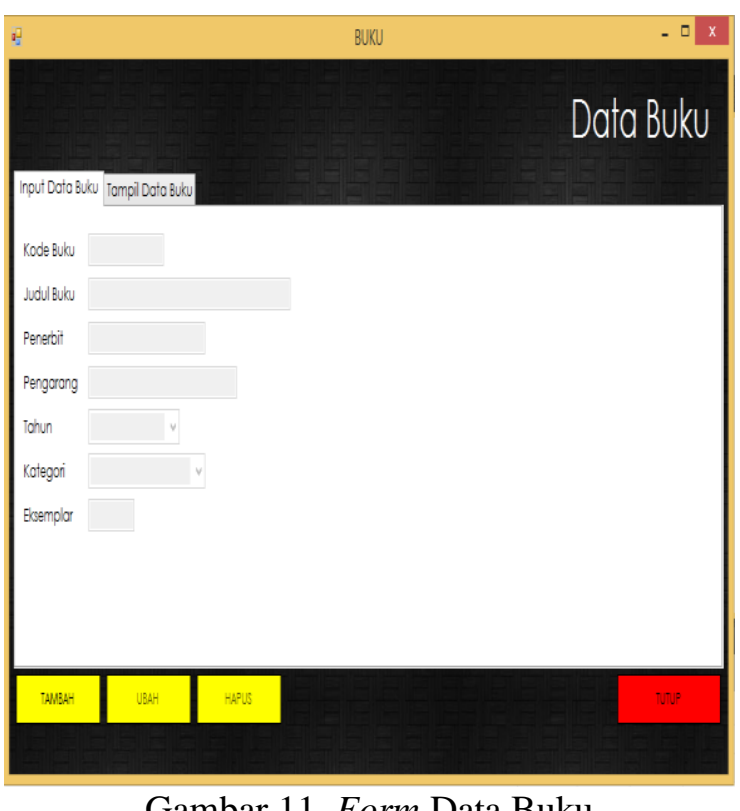

Gambar 11. Form Data Buku

e) Form Data User

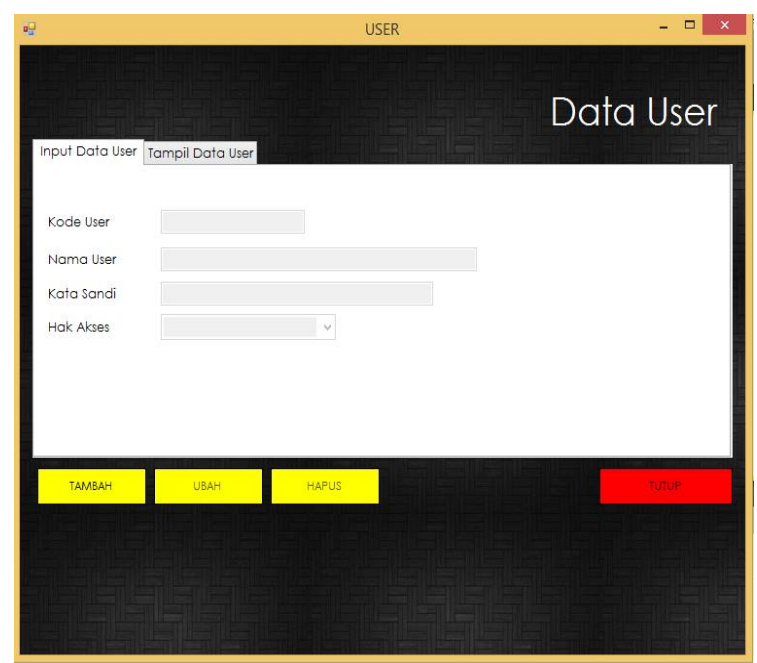

Gambar 12. Form Data User 
f) Form Peminjaman

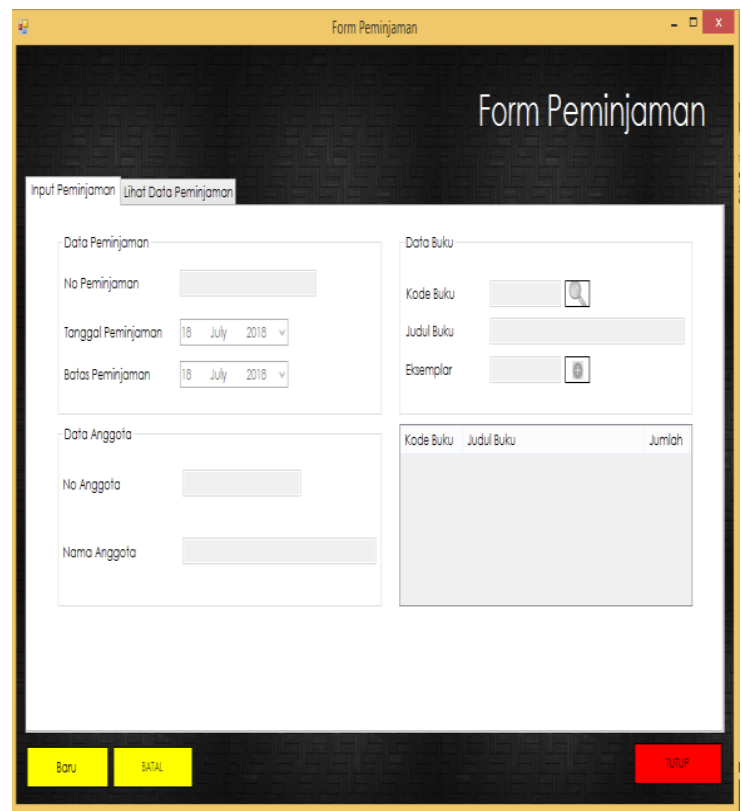

Gambar 13. Form Peminjaman

g) Form Pengembalian

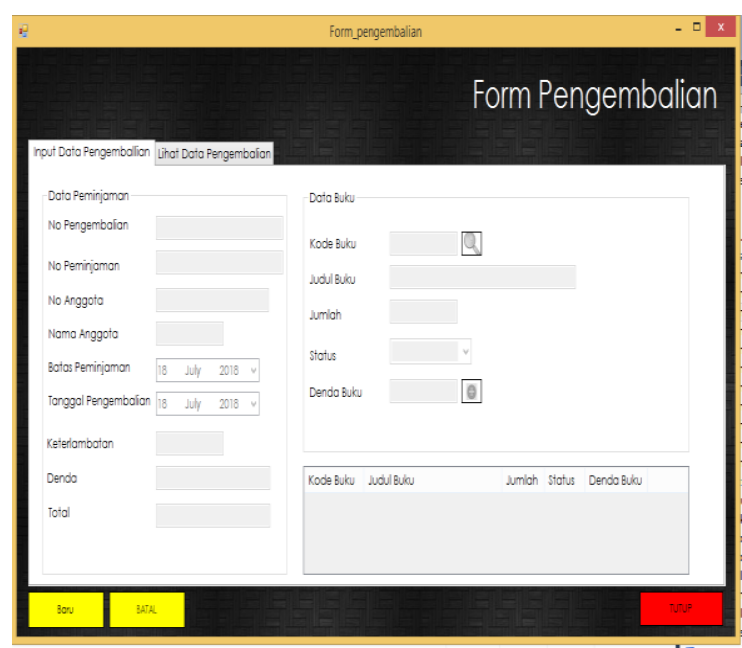

Gambar 14. Form Pengembalilan

\section{Kesimpulan dan Saran}

\section{Kesimpulan}

Adanya program perpustakaan ini peneliti mengambil kesimpulan sebagai berikut:

1. Program perpustakaan ini dapat sehingga proses dapat membantu kegiatan pendaftaran anggota serta transaksi peminjaman dan pengembalian diperpustakan berjalan dengan cepat.

2. Program perpustakaan ini dapat meminimalisir kehilangan data serta penduplikasian data karena data disimpan dalam sebuah database.

3. Perhitungan denda yang dilakukan pada saat transaksi pengembalian akan lebih cepat dan akurat karena perhitungan dilakukan secara otomatis.

4. Penyajian laporan yang dilakukan secara otomatis dapat mempermudah dalam penyampaian informasi kepada pihak sekolah.

\section{Saran}

Berdasarkan kesimpulan diatas, peneliti memberikan beberapa saran agar program perpustakaan ini dapat berjalan secara optimal, diantaranya sebagai berikut:

1. Diharapkan untuk mempunyai backup file.

2. Perlu adanya perawatan (maintenance) terhadap hardware maupun software yang dilakukan secara berkala.

3. Pengembangan terhadap rancangan program yang sudah ada seperti mencetak kartu anggota beserta foto anggota, pencetakan label buku sesuai eksemplar.

\section{Daftar Pustaka}

Afifah, Icha Isty Nur dan Supriyanta. 2018. Sistem Informasi penjualan Busana Pengantin Pada Tutut Manten Yogyakarta. Yogyakarta: Journal Speed. Vol 10, No 1. Diambil dari: https://repository.bsi.ac.id/index.php/brow se/index/?ref=submission\&author=Icha\% 2C+Isty+Nur+Afifah+Afifah

Ariansa, Erwin. 2015. Pengkodean Data. Diakses 25 April 2018 dari: http://www.lappara.web.id/2015/03/pengk odean-data.html?m=1.

Dudung. 2016. Pengertian, Komponen, dan Fungsi XAMPP Lengkap dengan Penjelasannya. Diakses 25 April 2018 dari: http://www.dosenpendidikan.com/pengerti an-komponen-dan-fungsi-xampp-lengkapdengan-penjelasannya/. 
Fadallah, M. F., dan Rosyida, S. 2018. Program Pemesanan Percetakan Berorientasi Objek Dengan Pemodelan Unified Modeling Language, (1), 61-70. Diambil dari: http://ejournalab.com/index.php/jsi/article/ view/210

Fikriansyah. 2017. Pengertian, Apa itu MySQL, Sejarah, dan Fungsinya. Diakses 25 April 2018 dari: https://www.tutorialpedia.net/apa-itumysql.

Lubis, Adyanata. 2016. Basis Data Dasar. Yogyakarta: Deepublish.

Mirawati dan Purnia, Dini Silvi. 2015. Pembangunan Sistem Informasi Perpustakaan Pada Sekolah Menengah Pertama Negeri 5 Ciamis. Ciamis: Jurnal Informatika. Vol 2, No 2. Diambil dari: https://ejournal.bsi.ac.id/ejurnal/index.php /ji/article/view/115/94

Pamungkas, Canggih Ajika. 2017. Pengantar dan Implementasi Basis Data. Yogyakarta: Deepublish.

Puspitasari, Diah. 2016. Sistem Informasi Perpustakaan Sekolah Berbasis Web. Bekasi: Jurnal Pilar Nusa Mandiri. Vol 12, No 2. Diambil dari: http://ejournal.nusamandiri.ac.id/ejurnal/in dex.php/pilar/article/view/181/157

Putera, Andi Rahman dan Ibrahim, Malik. 2018. Rancang Bangun Sistem Informasi Peminjaman dan Pengembalian Buku Perpustakaan SMP Negeri 1 Madiun. Madiun: Journal of Computer and Information Technology. Vol 1, No 2: 57 61. Diambil dari: http://ejournal.unipma.ac.id/index.php/doubleclic k/article/view/2025

Sahyar, M.S. 2016. Algoritma \& Pemrograman

Menggunakan Matlab
Laboratory). Jakarta: Kencana.

Shatu, Yayah Pudin. 2016. Kuasai Detail Akuntansi Laba \& Rugi. Jakarta: Pustaka Ilmu Semesta.

Sitorus, Lamhot. 2015. Algoritma dan Pemrograman. Yogyakarta: Andi Offset.

Sukamto, Rosa Ariani dan Muhammad Shalahuddin. 2018. Rekayasa Perangkat Lunak Terstruktur dan Berorientasi Objek. Bandung: Informatika.
Sukatmi. 2014. Implementasi White Box dan Black Box dalam Penjaminan Mutu Sistem Informasi. Vol 10, No 1. Diambil dari: http://ejurnal.dcc.ac.id/home.php?act=jurn al_detail\&\&idjurnal $=48$

Sopandi, Robi. 2018. Rancang Bangun Sistem Pendaftaran anggota BKK SMK Taruna karya 76 Nurul Falah Berbasis Web. Jakarta: Jurnal Bianglala Informatika. Vol 6, No 1. Diambil dari: http://jurnalbianglala.web.id/jurnal/index. php/bianglala/article/view/36

Yanto, Robi. 2016. Manajemen Basis Data Menggunakan MySQL. Yogyakarta: CV. Budi Utama.

Yesputra, Rolly. 2017. Belajar Visual Basic.Net dengan Visual Studio 2010. Kisaran: Royal Asahan Press.

Yulia, Eka Rini. 2017. Perancangan Program Penjualan Perhiasan Emas pada Toko Mas Dan Permata Renny Medan. Jakarta: Jurnal Evolusi. Vol 5, No 2. Diambil dari: https://repository.bsi.ac.id/index.php/undu h/item/1921/Eka-Rini-Yulia-(27-34)--PERANCANGAN-PROGRAMPENJUALAN-PERHIASAN-EMASPADA-TOKO-MAS-DAN-PERMATARENNY-MEDAN.pdf(29 April 2018) 